CONGENITAL SYPHILIS

By David Nabarro, M.D., F.R.C.P. Pp. xi + 470, with 95 illustrations. London: Edward Arnold Ltd. I954. 50s.

This monograph is based on nearly a thousand cases of congenital syphilis under the age of 12 which were dealt with by the author between 1917 and 1939 when he was in charge of the Venereal Diseases Clinic at the Hospital for Sick Children, Great Ormond Street, London. He discusses fully every aspect of the disease, rare or commonplace, and gives at length the views of many other writers both ancient and modern.

$\mathrm{He}$ is not dogmatic in his own conclusions, therefore, though one can strongly recommend this book to the expert, one would advise the less experienced to read the modern standard textbooks first.

He describes many cases the like of which may never be seen again in this country, but may well be met with in less civilized lands. Unfortunately, it cannot be helped that modern colour photography was not available when these patients were seen.

One whose working life ended in I 939 cannot be expected to have much first-hand knowledge of the great therapeutic advances of the last ten years and consequently his views on treatment are not quite up to date.

The historical chapter is particularly interesting and the references in the text and at the end of each chapter are most comprehensive and will be of great value to future authors.

The book is very well produced and the arrangement and index are excellent.

$$
\text { F.J.G.J. }
$$

\section{CLINICAL CHEMISTRY IN PRACTICAL MEDICINE}

By C. P. Stewart, D.Sc., PL.D. and D. M. Dunlop, B.A., M.D., F.R.C.P. 4th Edition. Pp. vii +320 , with 27 illustrations. Edinburgh: E. \& S. Livingstone, Ltd.. 1954. 21s.

This is an excellent book which can be thoroughly recommended to all who cannot spare the time to read a large text book. The information is clearly presented, with a practical emphasis everywhere. Appendices give concise descriptions of actual methods and tables of normal values. It is difficult to find anything that can be adversely criticised : future editions might contain a fuller and more accurate account of 'Water Retention' and describe the diagnosis and treatment of electrolyte abnormalities complicating the modern treatment of Congestive Failure. The Low Salt Syndrome deserves a section to itself. 'Plasma Potassium' could be extended from 16 lines to a page or twoperhaps at the expense of the 20 pages devoted to that anachronism the Fractional Test Meal. More space might also be given to the Electrophoresis (and the chromatography) of Proteins and the clinical use of I r 3r. Osteoporosis and Osteomalacia are curiously confused (Albright's usage is at least clear). The estimation of blood sugars in the fasting state and two hours after ingestion of $50 \mathrm{~g}$. glucose, as a substitute for the glucose tolerance test, would save clinical laboratories $\stackrel{\varnothing}{\complement}$ many hours of work. Lastly, the value of any $c$. book of this size is greatly increased by the inclusion $\vec{\Rightarrow}$ of a few well-chosen references at the end of each $\stackrel{9}{+}$ chapter.

\section{SURGERY OF THE CAECUM AND COLON}

By. Stanley Aylett, M.B.E., M.B., B.S., B.Sc., F.R.C.S. Pp. viii +295 , with 142 illustrations. Edinburgh: E. \& S. Livingstone, Ltd. 1954. 45s.

Mr. Aylett's monograph is orderly in its content and reasonable in its emphasis. Although based primarily on a wide personal experience, there is ample reference to the work of others. The operative descriptions, even if tediously repetitive (this in a commendable effort to avoid cross reference), are none the less clear and the illustrations with which it abounds, are wholly excellent. The reproductions of photographs and of X-rays, the type, the paper and the lay-out are of the quality which we have now come to expect from the House of Livingstone.

Mr. Aylett has always been the champion of ileorectal anastomosis in the treatment of multiple polyposis and of ulcerative colitis. Even if we are not convinced by his arguments, we must allow that he pleads his case again with the same vigous and enthusiasm as he does in surgical debate.

But the shortcomings of this book are none the less obvious. The quite inexcusably large number of typographical errors will surely disappear in a further edition and we can only hope that many of the ugly words, to which we too readily give acceptance in medical phraseology, will be quietly effaced. To 're-peritonealize,' 'epithelialized ' and 'diathermied ' we have almost become accustomed, but we must surely draw the line at "bowel sterilisant,' ' stricturing,' ' intussuscepted,' ' dilative ' and 'irresectable.'

Our main quarrel, however, is that the text is far too long; it could with profit be rigorously pruned. Surely arguments are none the less telling when they are short and to the point.

In the opening paragraph of the preface the author expresses the hope ' . . . that the pages which follow may fill a genuine gap on the over-burdened bookshelves of medical literature.' This volume can fairly he said to have filled the gap, but at the same time to have added quite unnecessarily to the burden.

M.R.E.

\section{MANSON'S TROPICAL DISEASES}

Edited by Sir Philip H. Manson-Bahr, C.M.G., D.S.O., M.A., M.D., D.T.M. \& H., F.R.C.P. I4th edition. Pp. xiv + I I44, with 440 illustrations, 15 in colour. London: Cassell \& Co., Ltd. r 954 . 6os.

It is 56 yizars since the first edition of this work 
was publishi:d and throughout that long period it has been the pre-eminent medium-sized volume in its subject. It was Manson's original intention to produce a volume 'of handy size and yet giving adequate information ... . for the exigencies of travel and of tropical life are, as a rule, incompatible with big volumes and large libraries.' This intention was carried out and has been kept in mind by its present editor, who is himself revising the book for the eighth time. His revision has been thorough and the material compressed into a little more than a thousand pages presents a balanced account of the principles and practice of tropical medicine. As a work of scholarship by a single author it can surely have seldom been surpassed.

Sufficient data is given of the pathological processes underlying the various diseases to enable the practitioner to understand them thoroughly while the practical aspects of differential diagnosis and treatment are given special prominence. In connection with the latter, there is a very valuable table of drugs occupying 18 pages of the text. In this the synonyms, composition, indications and dosages of the various substances are clearly stated. Regarding the former, an appendix covering 200 pages deals with medical zoology including medical protozoology, helminthology and entomology. It contains enough information to enable the practitioner to approach the various tropical diseases with understanding no matter how remotely situated from libraries he may be.

The publishers claim that the volume is almost unchallenged as the most authoritative and succinct account of the tropical diseases. It may fairly be claimed that they have not overstated their case.

A.W.W.

\section{ATOMIC MEDICINE}

Edited by Charles F. Behrens, M.D. Second edition. Pp. xiv +632 , with 100 illustrations. London: Baillière, Tindall \& Cox, Ltd. 1953. $84 s$.

'The Atom Knocks at the Doctor's Door' is the sub-heading to the preface of this book. Whatever the personal reaction is to such a catchphrase, no one can deny that nuclear physics has advanced the science of medicine and at the same time created new hazards to health. Until a decade ago the scientific contributions were of academic interest only and the health hazards strictly localized in a few centres handling radium. Now, with the release of nuclear energy in chain reactions on an industrial scale, many thousands are faced with new occupational risks. At the same time isotopes have become available in adequate amounts for diagnosis, therapy and research. Should world war recur millions of people may be exposed to the effects of atomic bomb explosions.

An obvious need arose for a book on the medical aspects of nuclear physics and the first edition of 'Atomic Medicine ' in 1949 was well received. The progress since has necessitated considerable revision in the new edition, though the general plan remains the same. There are chapters on the fundamentals of nuclear physics and radiation biology, and on the methods of detecting and measuring radiation; chapters devoted to the pathology, diagnosis and therapy of radiation injuries and to the use of radioactive isotopes in medicine. In addition, there are separate sections devoted to the atomic bomb and to civil defence. New sections in this edition are on dosimetry and particle acceleration and the tables have been revised and extended.

There are 20 authors to this book, all American, and the majority are members of the Medical Corps of the United States Navy. As a result there is considerable overlap between chapters and a tendency to ignore work done in countries other than the United States. Each chapter, however, stands on its own as a review of its subject matter and copious references are given. The value of the work is as a first-class reference book and not as an account of atomic energy to be read from cover to cover.

It was disappointing not to find a clear explanation of the roentgen as a unit of radiation dosage. For the average doctor, conditioned to the dosage of drugs, it is a difficult concept to comprehend and little help has been given in this book. There are a number of misprints and minor errors and there is a great variation in the standard of the diagrams. Many are good, but some are very poorly drawn, with lettering by a shaky hand or an indifferent typewriter. This is not excusable in the second edition of a small book costing four guineas. There seemed to be no good reason for including the detailed decay schemes of the natural radioactive series.

These defects merely caused the reviewer some irritation and do not reduce the value of the work to any marked extent. To those dealing with the medical aspects of nuclear physics it is a most useful book.

S.R.

\section{DENTAL AND ORAL X-RAY DIAGNOSIS}

By A. C. W. Hutchison, D.D.S., M.D.S., F.D.S., F.R.S.E., Pp. xii +524 , with 946 illustrations. Edinburgh: E. \& S. Livingstone, Ltd. 1954. 75s.

At the beginning of the preface the author states his object in presenting this textbook is to provide, within reasonable limits, a survey of the present position of dental and oral $\mathrm{X}$-ray diagnosis and, what is more important, to emphasize the need for a still closer co-operation between the pathologist, the clinician and the radiologist. In this he has been highly successful and at the same time he has produced a book which is easy and pleasant to read, which is an excellent reference book and which, by the inclusion of clinical features, pathology and aetiology, should be of great value to those trying to acquire additional knowledge.

A wise and sound foundation is laid by presenting pictures of the normal in the first chapters. As the 